\title{
ANALISA FUEL RATIO PLAN DAN ACTUAL ALAT ANGKUT ARTICULATED DUMP TRUCK VOLVO A35E DAN A40G PADA PENGANGKUTAN OVERBURDEN DI PT LDA, LAHAT, SUMATERA SELATAN
}

\author{
THE ANALYSIS OF PLANNED AND ACTUAL FUEL RATIO OF VOLVO A35E AND A40G \\ ARTICULATED DUMP TRUCK HAULING TOOLS ON THE OVERBURDEN PAULING \\ AT PT LDA, LAHAT, SOUTH SUMATRA
}

\author{
Edwin Harsiga ${ }^{1)}$, Andini Puspita Rahayu ${ }^{2)}$ \\ ${ }^{1,2)}$ Program Studi Teknik Pertambangan Batubara Politeknik Akamigas Palembang, 30257, Indonesia \\ Corresponding Author E-mail: edwinharsiga@pap.ac.id dan puspitarahayuandini@gmail.com
}

\begin{abstract}
PT LDA is a company engaged in mining services which is a company engaged in the contracting business. The biggest need to support mining activities is mechanical equipment. The excessive use of fuel can affect the company's profits. The comparison between fuel consumption and productivity is called the fuel ratio. If the actual fuel ratio is lower than the planned fuel ratio, the company will gain profit and vice versa. The productivity realization in May of Volvo A35E was 69.225 BCM/hour fuel consumption of 26,09 liters/hour and for the realization of Volvo $\mathrm{A} 40 \mathrm{G}$ was $75.780 \mathrm{BCM} /$ hour with the fuel consumption of 25,46 liter/hour. Meanwhile, The productivity realization in April of Volvo A35E was $60.197 \mathrm{BCM} /$ hour with the fuel consumption of 26,35 liter/hour and the realization of Volvo A40G was 64,764 BCM'hour with the fuel consumption of 25,51 liter/hour. In March, the planned fuel ration for Volvo A35E was 0,327 liter/BCM while the actual fuel ratio was 0,376 liter/BCM and the planned fuel ratio for Volvo A40G was 0,294 liter/BCM while the actual fuel ratio was 0,335 liter/BCM. In April, the planned fuel tation for Volvo A35E was 0,366 liter/BCM while the actual fuel ratio was 0,437 liter/BCM and the planned fuel ratio for Volvo A40G was 0,329 liter/BCM while the actual fuel ratio was 0,393 liter /BCM. Since the actual fuel ratio was higher that the planned fuel ratio indicated the company's loss. The loss incurred by PT Langgeng Daya Agrindo in March of Volvo A35E was Rp 66.246.248,25 per month and the loss of the Volvo A40G- was Rp 62.356.633,92 per month while in April the loss of Volvo A3SE articulated dump truck unit IDR 63.806.893,69 per month and the loss of Volvo A40G was Rp 72.995.401,21 per month.

Keywords: Fuel consumption, fuel ratio, loss.
\end{abstract}

Abstrak: PT LDA adalah perusahaan yang bergerak dalam jasa penambangan yang merupakan perusahaan yang bergerak dalam bisnis kontraktor. Kebutuhan terbesar dalam menunjang kegiatan penambangan adalah peralatan mekanis. Penggunaan bahan bakar yang berlebihan dapat berpengaruh terhadap keuntungan perusahaan. Perbandingan antara konsumsi bahan bakar dengan produktivitas disebut fuel ratio. Apabila fuel ratio actual lebih kecil dari fuel ratio plan maka perusahaan akan mendapat keuntungan begitu juga sebaliknya. Realisasi produktivitas pada bulan Maret untuk unit articulated dump truck Volvo A35E sebesar 69,225 BCM/jam dengan konsumsi bahan bakar 26,09 liter/jam dan untuk realisasi unit articulated dump truck Volvo A40G sebesar 75,780 BCM/jam dengan konsumsi bahan bakar 25,46 liter/jam. Sedangkan realisasi produktivitas pada bulan April untuk unit articulated dump truck Volvo A35E sebesar 60,197 BCM/jam dengan konsumsi bahan bakar 26,35 liter/jam dan untuk realisasi unit articulated dump truck Volvo A40G sebesar 64,764 BCM/jam dengan konsumsi bahan bakar 25,51 liter/jam. Pada bulan Maret fuel ratio plan untuk unit articulated dump truck Volvo A35E sebesar 0,327 liter/BCM sedangkan fuel ratio actual sebesar 0,376 liter/BCM dan fuel ratio plan untuk unit articulated dump truck Volvo A40G sebesar 0,294 liter/BCM sedangkan fuel ratio actual sebesar 0,335 liter/BCM. Pada bulan April fuel ratio plan untuk unit articulated dump truck Volvo A35E sebesar 0,366 liter/BCM sedangkan fuel ratio actual sebesar 0,437 dan fuel ratio plan untuk unit articulated dump truck Volvo A40G sebesar 0,329 liter/BCM sedangkan fuel ratio actual sebesar 0,393 liter/BCM. Karena fuel ratio actual lebih besar dari fuel ratio plan menunjukan kerugian yang dialami perusahaan. Kerugian yang dikeluarkan oleh PT Langgeng Daya Agrindo pada bulan Maret untuk unit articulated dump truck Volvo A35E sebesar Rp66.246.248,25 rupiah/bulan dan untuk unit articulated dump truck Volvo A40G kerugiannya sebesar Rp62.356.633,92 rupiah/bulan sedangkan pada bulan April untuk unit articulated dump truck Volvo A35E sebesar Rp63.806.893,69 rupiah/bulan dan untuk unit articulated dump truck Volvo A40G sebesar Rp72.985.401,21 rupiah/bulan.

Kata kunci: Fuel Consumption, Fuel Ratio, Kerugian. 


\section{PENDAHULUAN}

\subsection{Latar Belakang}

Banyak kebutuhan yang diperlukan untuk menunjang kegiatan dari penambangan yang dilakukan oleh suatu perusahaan. Salah satu kebutuhan terbesar dalam menunjang kegiatan penambangan merupakan bahan bakar. Bahan bakar memiliki fungsi untuk menggerakan alat-alat mekanis yang mendukung kegiatan penambangan agar target produksi tercapai. Produksi merupakan banyaknya material yang dapat digali atau dipindahkan persatuan waktu. Produktivitas dapat dinyatakan berhasil jika alat mekanis mampu memenuhi target produksi dengan menggunakan konsumsi bahan bakar seminimal mungkin. Bahan bakar yang digunakan pada PT LDA adalah bahan bakar biosolar B30, biosolar B30 adalah campuran biodiesel berbasis kelapa sawit sebanyak $30 \%$ dalam minyak solar.

Penggunaan bahan bakar dapat dilihat dari fuel ratio untuk mengetahui perusahaan mengalami kerugian atau mendapat keuntungan yang lebih kecil jika bahan bakar yang digunakan berlebihan fuel ratio merupakan perbandingan antara total konsumsi bahan bakar dan total produksi. Apabila fuel ratio melebihi standar yang telah ditentukan, maka perusahaan perlu dilakukan evaluasi terhadap produktivitas dan produksi overburden serta penggunaan bahan bakar, sehingga dengan adanya nilai dari fuel ratio plan dan mencari nilai fuel ratio actua, maka akan memperlihatkan perusahaan memperoleh keuntungan atau bisa juga mendapat kerugian.

Pada bulan Maret 2021 terdapat permasalahan kenaikan fuel ratio sebesar 0,5 liter/bcm pada unit articulated dump truck Volvo A35E dan 0,04 liter/bcm pada unit articulated dump truck Volvo A40G sedangkan pada bulan April 2021 kenaikan fuel ratio sebesar 0,7 liter/bcm pada unit articulated dump truck Volvo A35E dan 0,06 liter/bcm pada unit articulated dump truck Volvo A40G.

\subsection{Batasan Masalah}

yaitu:

Batasan masah pada penelitian ini,

1. Jenis alat yang diteliti yaitu articulated dump truck Volvo A35E dan articulated dump truck Volvo A40G di PT LDA.

2. Konsumsi bahan bakar alat angkut articulated dump truck Volvo A35E dan articulated dump truck Volvo A40G pada bulan Maret-April 2021 di PT LDA.

3. Perbandingan fuel ratio plan dan fuel ratio actual pada bulan Maret-April 2021 di PT LDA.

4. Menghitung kerugian penggunaan konsumsi bahan bakar yang dialami oleh perusahaan pada pengangkutan overburden pada bulan Maret-April 2021 di PT LDA.

\subsection{Tujuan Penelitian}

Tujuan dari penelitian ini, yaitu:

1. Menghitung produktivitas alat angkut articulated dump truck Volvo A35E dan A40G pada kegiatan pengangkutan di PT LDA.

2. Menghitung konsumsi bahan bakar untuk articulated dump truck Volvo A35E dan A40G pada kegiatan pengangkutan overburden pada bulan Maret dan April di PT LDA.

3. Menganalisa dan membandingkan fuel ratio plan dan fuel ratio actual pada kegiatan penangkutan overburden di PT LDA.

4. Menghitung kerugian yang dialami perusahaan akibat konsumsi bahan bakar pada kegiatan pengangkutan overburden pada bulan Maret dan April 2021 di PT LDA.

\subsection{Manfaat}

Manfaat dari penelitian ini, yaitu:

1. Mampu menjelaskan bagaimana cara menghitung produktivitas, konsumsi bahan bakar, fuel ratio, dan kerugian yang dialami perusahaan akibat konsumsi bahan bakar articulated dump truck Volvo A40G dan articulated dump truck Volvo A40G terhadap jarak di PT LDA. 
2. Menjadi bahan pertimbangan perusahaan dalam realisasi biaya konsumsi bahan bakar di PT LDA.

\section{TEORI DASAR}

\subsection{Konsumsi Bahan Bakar}

Konsumsi bahan bakar dipengaruhi oleh kondisi mesin setiap alat, kinerja operator dalam menjalankan alat- alat tersebut, dan kondisi kerja pada saat alat-alat tersebut bekerja. Konsumsi bahan bakar ini sangat mempengaruhi biaya operasi perusahaan. Untuk mengetahui jumlah konsumsi bahan bakar dapat dihitung menggunakan rumus sebagai berikut (Merlin, 2016:28):

Dimana:

$$
\mathrm{FC}=\frac{\text { Total } \mathrm{FC}}{\text { Operating Hours }(\mathrm{OH})}
$$

FC = konsumsi bahan bakar (liter/jam)

Total FC= total FC (liter/bulan)

$\mathrm{OH} \quad=$ waktu kerja $(\mathrm{jam} / \mathrm{bulan})$

\subsection{Produktivitas Alat Angkut}

Menurut Tenriajeng (2003) dasar pengoperasian dump truck meliputi loading, hauling, dumping, dan returning. Untuk menghitung besarnya produksi dump truck per jam dapat ditentukan sebagai berikut:

Dimana :

$$
\mathrm{Q}=\frac{\mathrm{n} \times \mathrm{Kb} \times 360 \times \mathrm{FF} \times \mathrm{Sf} \times \mathrm{Eff}}{\mathrm{CT}}
$$

Q = produksi alat angkut $\left(\mathrm{m}^{3} / \mathrm{jam}\right)$

$\mathrm{n} \quad=$ jumlah pengisian

$\mathrm{Kb} \quad=$ kapasitas muat bucket $\left(\mathrm{m}^{3}\right)$

$\mathrm{FF} \quad=$ faktor pengisian bucket $(\%)$

Sf = swelling factor

Eff = efisiensi kerja dump truck (\%)

CT = waktu edar (detik)

\subsection{Fuel Ratio}

Merupakan nilai rasio yang menunjukkan perbandingan antara penggunaan bahan bakar (liter/jam) dengan produksi yang dihasilkan (bcm/jam). Penggunaan fuel ratio bertujuan agar dapat mengetahui seberapa banyak konsumsi bahan bakar yang diperlukan sehingga dapat mengontrol biaya produksi. Fuel ratio sangat mempengaruhi suatu perusahaan tambang akan memperoleh keuntungan atau kerugian, karena anggaran fuel ratio termasuk dalam anggaran besar dalam kegiatan operasi produksi. Nilai fuel ratio dapat dihitung dengan rumus sebagai berikut (Merlin,2016:36):

$$
\mathrm{FR}=\frac{\text { Jumlah Konsumsi Bahan Bakar }}{\text { Produktivitas }}
$$

Mencari biaya yang dikeluarkan untuk konsumsi bahan bakar dapat menggunakan persamaan (Anggraini, 2019:12):

Total Biaya BBM = Konsumsi BBM/jam x Harga BBM/liter

Sedangkan untuk menghitung total biaya kerugian menggunakan persamaan:

$$
\mathrm{K}=\left(\mathrm{FR}_{\mathrm{a}}-\mathrm{FR}_{\mathrm{p}}\right) \times \mathrm{TP}_{\mathrm{a}} \times \mathrm{P}
$$

Dimana:

$\mathrm{K} \quad$ = kerugian

$\mathrm{FR}_{\mathrm{a}} \quad$ = fuel ratio actual

$\mathrm{FR}_{\mathrm{p}} \quad=$ fuel ratio plan

$\mathrm{TP}_{\mathrm{a}} \quad=$ total produksi aktual

$\mathrm{P} \quad=$ harga $\mathrm{BBM}$

Perusahaan akan menghitung berapa besar fuel ratio plan supaya pada akhir bulan dapat dibandingkan dengan fuel ratio actual, apabila:

1. Fuel ratio plan lebih besar dari fuel ratio actual, perusahaan memperoleh keuntungan.

2. Fuel ratio actual lebih besar dari fuel ratio plan, perusahaan memperoleh kerugian.

\section{METODOLOGI PENELITIAN} 3.1 Waktu dan Tempat Penelitian

Penelitian ini dilaksanakan pada tanggal 22 Maret s.d. 21 April 2021. Tempat penelitian ini di PT LDA site X.

\subsection{Metode Penelitian}

\subsubsection{Teknik Pengumpulan Data}

Teknik pengumpulan data yang digunakan dalam penelitian ini adalah dengan pendekatan deskriptif, yaitu dengan cara pengamatan dan penelitian dilapangan kemudian dianalisa, dibandingkan dan dihitung secara teoritis sehingga diperoleh solusi yang terbaik. 


\subsubsection{Teknik Pengambilan Data}

Teknik pengambilan data penelitian ini adalah:

1. Studi literatur

Studi literatur dilakukan dengan mencari studi pustaka yang menunjang dalam penelitian ini.

2. Observasi lapangan

Metode ini dilakukan dengan cara mengamati langsung aktivitas penambangan dan informasi pendukung yang terkait dengan permasalahan yang menyebabkan terjadinya perbedaan antara fuel ratio plan dan fuel ratio actual pada kegiatan pengangkutan overburden pada alat angkut di PT LDA.

3. Wawancara

Wawancara merupakan teknik pengumpulan data dengan cara mengadakan diskusi secara langsung dengan pembimbing lapangan dan pegawai yang ada di PT LDA.

\section{HASIL DAN PEMBAHASAN}

4.1 Produktivitas Plan dan Actual Alat Angkut ADT Volvo A35E

Produktivitas plan alat angkut merupakan kemampuan suatu alat untuk memindahkan material biasanya dinyatakan dalam satuan BCM/jam. Target produktivitas pada bulan Maret 2021 pada articulated dump truck volvo A35E dapat dilihat pada tabel 4.1.

Tabel 4.1 Produktivitas Plan Volvo A35E

\begin{tabular}{|l|l|}
\hline Bulan & Produktivitas \\
\hline Maret & $81 \mathrm{BCM} /$ jam \\
\hline April & $75 \mathrm{BCM} /$ jam \\
\hline
\end{tabular}

Produktivitas actual alat angkut ADT Volvo A35E dapat dilihat pada tabel 4.2.

Tabel 4.2 Produktivitas Actual Volvo A35E

\begin{tabular}{|l|l|}
\hline Bulan & Produktivitas \\
\hline Maret & $60,225 \mathrm{BCM} / \mathrm{jam}$ \\
\hline April & $60,197 \mathrm{BCM} / \mathrm{jam}$ \\
\hline
\end{tabular}

\subsection{Produktivitas Plan dan Actual Alat Angkut ADT Volvo A40G}

Target produktivitas pada bulan Maret 2021 pada articulated dump truck volvo A40G dapat dilihat pada tabel 4.3.
Tabel 4.3 Produktivitas Plan ADT Volvo A40G

\begin{tabular}{|l|l|}
\hline Bulan & Produktivitas \\
\hline Maret & $85 \mathrm{BCM} / \mathrm{jam}$ \\
\hline April & $79 \mathrm{BCM} / \mathrm{jam}$ \\
\hline
\end{tabular}

Produktivitas actual alat angkut ADT Volvo A40G dapat dilihat pada tabel 4.4.

Tabel 4.4 Produktivitas Actual Volvo A40G

\begin{tabular}{|l|l|}
\hline Bulan & Produktivitas \\
\hline Maret & $75,780 \mathrm{BCM} /$ jam \\
\hline April & $64,764 \mathrm{BCM} /$ jam \\
\hline
\end{tabular}

\subsection{Pemakaian Bahan Bakar Articulated Dump Truck Volvo}

Pemakaian bahan bakar alat angkut yang digunakan, pada unit articulated dump truck Volvo A35E dan A40G dapat diketahui melalui data bulanan, mingguan maupun harian. Adapun unit hauler yang dilakukan penelitian berjumlah 11 unit dimana 6 unit merupakan articulated dump truck Volvo A35E dan 5 unit merupakan articulated dump truck Volvo A40G.

\subsubsection{Pemakaian Solar Plan dan Actual ADT A35E}

Konsumsi bahan bakar plan alat angkut ADT Volvo A35E dapat dilihat pada tabel 4.5.

Tabel 4.5 Fuel Consumption Plan A35E

\begin{tabular}{|l|l|}
\hline Bulan & Fuel Consumption \\
\hline Maret & 26,5 liter/jam \\
\hline April & 27,5 liter/jam \\
\hline
\end{tabular}

Konsumsi bahan bakar actual alat angkut ADT Volvo A35E dapat dilihat pada tabel 4.6.

Tabel 4.6 Fuel Consumption Actual A35E

\begin{tabular}{|l|l|}
\hline Bulan & Fuel Consumption \\
\hline Maret & 26,09 liter/jam \\
\hline April & 26,35 liter/jam \\
\hline
\end{tabular}

\subsubsection{Pemakaian Solar Plan dan Actual ADT A40G}

Konsumsi bahan bakar plan alat angkut ADT Volvo A40G dapat dilihat pada tabel 4.7. 
Tabel 4.7 Fuel Consumption Plan A40G

\begin{tabular}{|l|l|}
\hline Bulan & Fuel Consumption \\
\hline Maret & 25 liter/jam \\
\hline April & 26 liter/jam \\
\hline
\end{tabular}

Konsumsi bahan bakar actual alat angkut ADT Volvo A40G dapat dilihat pada tabel 4.8.

Tabel 4.8 Fuel Consumption Actual A40G

\begin{tabular}{|l|l|}
\hline Bulan & Fuel Consumption \\
\hline Maret & 25,46 liter/jam \\
\hline April & 25,51 liter/jam \\
\hline
\end{tabular}

\subsection{Fuel Ratio Plan dan Actual}

4.3.1 Fuel Ratio Plan dan Actual ADT Volvo A35E Bulan Maret 2021

Perbandingan produktivitas dengan konsumsi bahan bakar plan maupun actual (liter/BCM) dapat dilihat pada gambar 4.1.

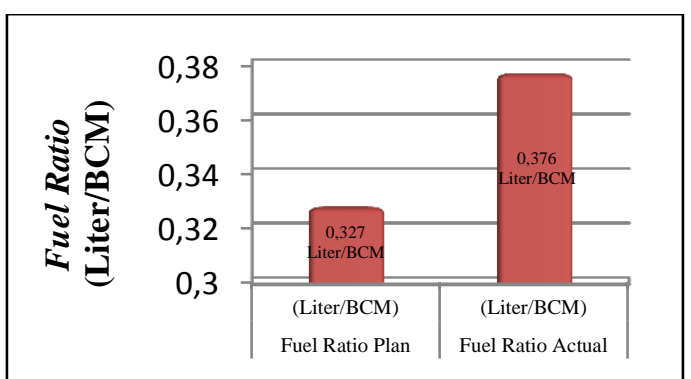

Gambar 4.1 Fuel Ratio Plan dan Actual A35E

Didapatkan nilai fuel ratio plan 0,327 liter/BCM dan fuel ratio actual 0,376 liter/BCM pada ADT Volvo A35E.

\subsubsection{Fuel Ratio Plan dan Actual ADT}

Volvo A40G Bulan Maret 2021

Perbandingan produktivitas dengan konsumsi bahan bakar plan maupun actual (liter/BCM) dapat dilihat pada gambar 4.2.

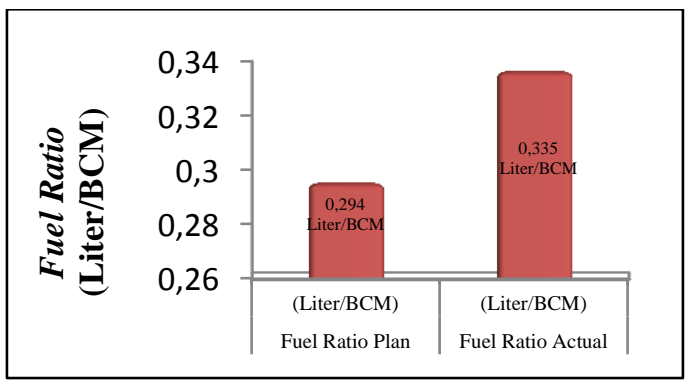

Gambar 4.2 Fuel Ratio Plan dan Actual A40G
Didapatkan nilai fuel ratio plan 0,294 liter/BCM dan fuel ratio actual 0,335 liter/BCM pada ADT Volvo A40G

\subsubsection{Fuel Ratio Plan dan Actual ADT} Volvo A35E Bulan April 2021

Berdasarkan perhitungan perbandingan produktivitas dengan konsumsi bahan bakar plan maupun actual (liter/BCM) didapatkan nilai fuel ratio plan 0,366 liter/BCM dan fuel ratio actual 0,437 liter/BCM pada ADT Volvo A35E yang dapat dilihat pada gambar 4.3.

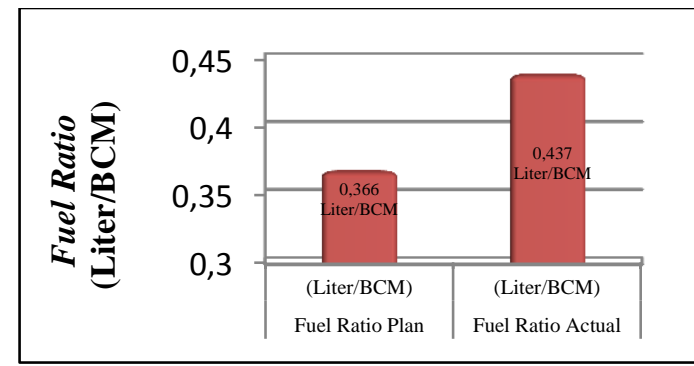

Gambar 4.3 Fuel Ratio Plan dan Actual A35E

\subsubsection{Fuel Ratio Plan dan Actual ADT Volvo A40G Bulan April 2021}

Dari perhitungan perbandingan produktivitas dengan konsumsi bahan bakar plan maupun actual (liter/BCM) didapatkan nilai fuel ratio plan 0,329 liter/BCM dan fuel ratio actual 0,393 liter/BCM pada ADT Volvo A40G yang dapat dilihat pada gambar 4.4.

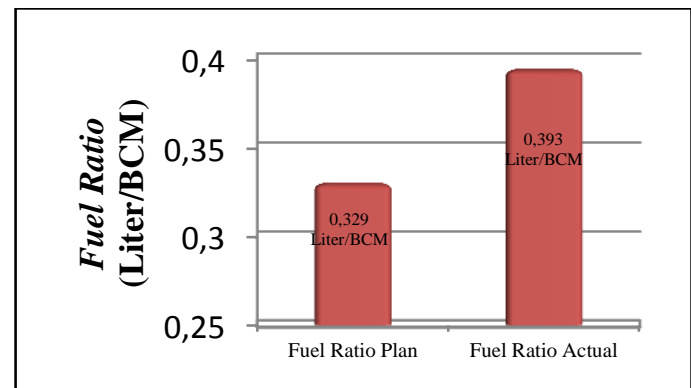

Gambar 4.4 Fuel Ratio Plan dan Actual A40G

\subsection{Total Kerugian Perusahaan}

4.4.1 Total Kerugian Perusahaan pada Bulan Maret 2021

Kerugian yang dikeluarkan perusahaan pada bulan Maret 2021 untuk unit articulated dump truck Volvo A35E dengan selisih fuel ratio 0,05 dan total produksi 122.112.900 
BCM/bulan serta harga bahan bakar Rp10.850,00 per liter mengeluarkan kerugian sebesar Rp66.246.248,25 rupiah/bulan. Sedangkan pada unit articulated dump truck Volvo A40G dengan selisih fuel ratio 0,04 total produksi $143.678,880 \mathrm{BCM} /$ bulan serta harga bahan bakar Rp10.850,00, maka mengeluarkan kerugian sebesar Rp62.356.633,92 rupiah/bulan.

\subsubsection{Total Kerugian Perusahaan pada Bulan April 2021}

Kerugian yang dikeluarkan perusahaan pada bulan Maret 2021 untuk unit articulated dump truck Volvo A35E dengan selisih fuel ratio 0,07 dan total produksi $81.386,344$ BCM/bulan serta harga bahan bakar Rp11.200,00 per liter mengeluarkan kerugian sebesar Rp63.806.893,69 rupiah/bulan. Sedangkan pada unit articulated dump truck Volvo A40G dengan selisih fuel ratio 0,06 total produksi 108.609,228 $\mathrm{BCM} /$ bulan serta harga bahan bakar Rp11.200,00 maka mengeluarkan kerugian sebesar Rp72.985.401,21 rupiah/bulan.

\subsection{Pembahasan}

Produktivitas alat angkut articulated dump truck Volvo A40G lebih besar dari articulated dump truck Volvo A35E dikarenakan kapasitas vassel yang dimiliki articulated dump truck Volvo A40G lebih besar. Produktivitas di PT LDA pada bulan Maret tidak mencapai target karena pada bulan tersebut kondisi jalan angkut yang tidak rata serta jalan angkut digunakan tersebut digunakan besama dengan PT berbeda dimana letak PT tersebut berdekatan dengan PT LDA tempat peneliti melakukan pengamatan tugas akhir. Jalan angkut yang digunakan secara bersamaan menyebabkan operator terkadang terhenti ketika ada alat angkut dari PT lain yang akan lewat memotong jalan. Kondisi tersebut membuat penambahan pada waktu edar alat angkut sehingga mempengaruhi pencapaian produktivitas dari alat angkut tersebut, penggunaan jalan angkut secara bersamaan terjadi karena tumpukan overburden di bulan Februari 2021 pada disposal point di PT LDA runtuh dan menutup jalan angkut milik PT lain yang dekat dengan PT LDA, sehingga dengan menunggu perbaikan yang dilakukan jalan angkut digunakan secara bersamaaan. Selain faktor kondisi jalan faktor ketersediaan alat menjadi penyebab rendahnya produktivitas pada bulan ini. Sedangkan pada bulan April 2021 jarak disposal point lebih jauh dari bulan Maret 2021, sehingga produktivitas plan yang digunakan pada bulan April 2021 lebih kecil dari bulan Maret. Namun, akibat penambahan jarak pada bulan April 2021 serta kondisi jalan yang masih sama dengan bulan Maret 2021 dan ketersediaan alat angkut yang tidak memenuhi target menyebabkan produktivitas actual pada bulan April 2021 lebih kecil dari bulan Maret 2021. Perbaikan serta perawatan alat angkut yang kurang baik menjadi penyebab ketersediaan alat angkut yang sering tidak mencukupi di lapangan. Dengan ketersediaan alat angkut yang tidak mencukupi membuat fuel ratio actual lebih tinggi dari fuel ratio plan perusahaan karena kurangnya unit alat angkut di lapangan akan berpengaruh pada pencapaian produksi perusahaan. Alat angkut saat sedang berada di workshop dapat dilihat pada gambar 4.5.

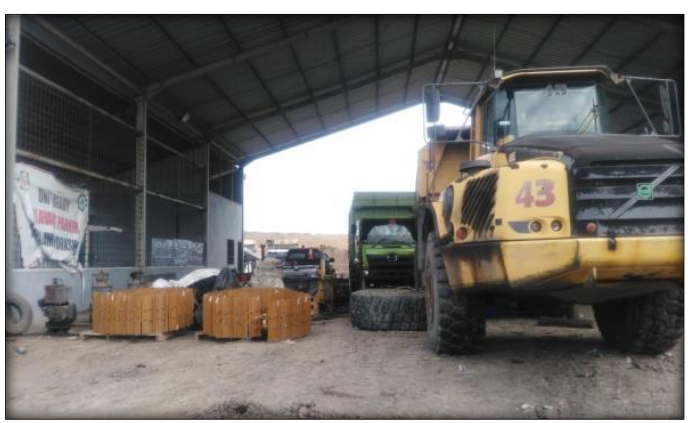

Gambar 4.5 Kondisi Alat Angkut

Pada saat alat angkut sedang berada di workshop dan akan dilakukan perbaikan sering memakan waktu yang cukup lama terlebih ketika kebutuhan spare part yang dibutuhkan sedang tidak tersedia. Selain itu, kendala yang sering terjadi pada ketersediaan alat karena ketika unit sedang terjadi kerusakan, maka yang diperbaiki hanya kerusakan yang terjadi saja dan tidak dilakukan pengecekan lain sehingga pada saat alat angkut sedang 
beroperasi kembali sering terjadi kerusakan lain yang menyebabkan alat angkut harus kembali masuk ke workshop untuk dilakukan perbaikan. Kondisi alat angkut yang sedang dilakukan perbaikan dapat dilihat pada gambar 4.6.

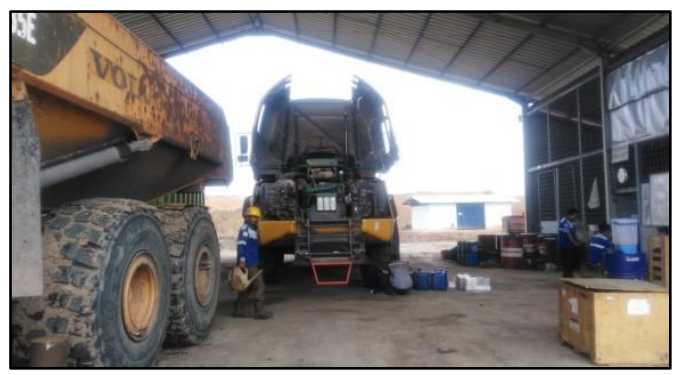

Gambar 4.6 Perbaikan Alat Angkut

Dari faktor jalan angkut yang tidak rata, ketersediaan alat dan kemajuan jarak pada disposal point dapat menjadi penyebab penurunan produktivitas juga menjadi penyebab kenaikan konsumsi bahan bakar. Jalan angkut yang tidak rata ketika hujan turun akan membuat jalan setelah hujan menjadi licin sehingga alat angkut akan bergerak lebih pelan sedangkan pada kemajuan jarak disposal point di bulan April 2021 menyebabkan konsumsi bahan bakar per jam dibulan April 2021 lebih tinggi dari konsumsi bahan bakar bulan Maret 2021. Semakin banyak faktor yang menghambat laju alat angkut, maka akan semakin lama waktu edar (cycle time) dari alat angkut. Kenaikan fuel ratio actual menyebabkan perusahaan mengalami kerugian dimana kerugian yang dikeluarkan perusahaan seharusnya dapat diatasi dengan planning maintenance sehingga dapat menekan pengeluaran perusahaan

\section{KESIMPULAN DAN SARAN \\ 5.1 Kesimpulan}

Dari penelitian yang telah dilakukan, maka dapat disimpulkan

1. Pada bulan Maret 2021 realisasi produktivitas articulated dump truck Volvo A35E sebesar 69,225 BCM/jam dan produktivitas articulated dump truck Volvo A40G sebesar 75,780 BCM/jam. Sedangkan produktivitas pada bulan April 2021 articulated dump truck Volvo A35E sebesar 60,197 BCM/jam dan relialisasi produktivitas articulated dump truck Volvo A40G sebesar 64,764 BCM/jam. Tidak tercapainya produktivitas secara actual karena faktor kondisi jalan, jarak disposal point yang bertambah serta ketersediaan alat angkut yang tidak terpenuhi.

2. Pada bulan Maret 2021 realisasi konsumsi bahan bakar articulated dump truck Volvo A35E sebesar 26,09 liter/jam dan konsumsi bahan bakar articulated dump truck Volvo A40G sebesar 25,46 liter/jam. Sedangkan konsumsi bahan bakar pada bulan April 2021 articulated dump truck Volvo A35E sebesar 26,35 liter/jam dan konsumsi bahan bakar articulated dump truck Volvo A40G sebesar 25,51 liter/jam. Kenaikan konsumsi bahan bakar juga dikarenakan faktor yang menyebabkan penurunan produktivitas, terlebih pada bulan April jarak disposal tidak sama dengan bulan Maret.

3. Pada bulan Maret 2021 selisih fuel ratio plan dan fuel ratio actual articulated dump truck Volvo A35E sebesar 0.05 dan selisih fuel ratio plan dan fuel ratio actual articulated dump truck Volvo A40G sebesar 0,04. Sedangkan Pada bulan April 2021 selisih fuel ratio plan dan fuel ratio actual articulated dump truck Volvo A35E sebesar 0,07 dan selisih fuel ratio plan dan fuel ratio actual articulated dump truck Volvo A40G 0,06. Kenaikan fuel ratio actual disebabkan karena pemakaian bahan bakar tidak sebanding dengan pencapaian produktivitas yang rendah.

\subsection{Saran}

Dari pembahasan yang telah dilakukan, maka dapat disarankan perusahaan harus melakukan planning maintenance yang baik pada alat angkut dan kondisi jalan angkut, supaya tidak menyebabkan kurangnya produktivitas alat angkut dalam bekerja yang dapat mempengaruhi kenaikan fuel ratio actual di perusahaan.

\section{DAFTAR PUSTAKA}

Anggraini, Mila. 2019. Perhitungan Perbandingan Fuel Ratio Plan dan Fuel Ratio Aktual Alat Angkut Articulated Dump Truck 
Cat D400E Pada Kegiatan stripping Overburden. Politeknik Akamigas Palembang: "Tugas Akhir Tidak diterbitkan".

Anonim. 2006. Specification And Application Handbook, 27 th Edition. Volvo, Ltd.

Nabella, Merlin dkk. 2016. Analisis Kemiringan Jalan dan Jarak Angkut Terhadap Konsumsi Bahan Bakar dan Fuel Ratio Pada Kegiatan Penambangan Batubara. Bandung: Univesitas Islam Bandung.

Tenriajeng, Andi Tenrisukki. 2003. Pemindahan Tanah Mekanis. Jakarta: Gunadarma. 